\title{
Increasing Voltage Utilisation in Split-Link, Four-Wire Inverters
}

\author{
Jun Liang* Tim C. Green Chunmei Feng and George Weiss \\ School of Engineering Electrical and Electronic Engineering \\ University of Cardiff Imperial College London \\ Cardiff CF24 3AA, U.K. $\quad$ London SW7 2AZ, U.K.
}

Abstract - Four-wire inverters are useful for interfacing distributed generation to networks of unbalanced loads but neither of the available circuit topologies is ideal. The split-link 3-leg topology (with 6 switches) suffers poor DC voltage utilisation compared to the 4-leg topology (with 8 switches). The 4-leg topology has an EMC difficulty because it imposes large amplitude high-frequency voltages between the DC-link busbars and ground. To obtain both good DC voltage utilisation and good EMC performance, it is proposed to use a split-link inverter with an active balancing circuit (also 8 switches). The balancing circuit is used to modulate the DC busbar offset voltage to make better use of the available DC-link voltage. The optimum voltage term is established to be a third harmonic term and the utilisation improves to that of the 4-leg inverter. A deadbeat controller supplemented with a repetitive controller is designed to give good tracking and good disturbance rejection for the busbar offset voltage. System performance is studied through an experimental test rig.

Index Terms - four-wire inverter, DC-link, voltage utilisation, busbar offset modulation, repetitive control

* Corresponding author: Dr Jun Liang, School of Engineering, Cardiff University, CF24 3AA, UK. Tel: +44-29 2087 0666. Fax: +44-29 2087 4716. E-mail: liangj1@cardiff.ac.uk.

This work was supported by the EPSRC (www.epsrc.ac.uk) under Portfolio Partnership Grant GR/S61256/01 


\section{INTRODUCTION}

When a distribution network supplied by inverters has unbalanced loads, a four-wire inverter (with a neutral connection in addition to three phase connections) can be used to provide full control over the phase voltages and thereby ensure good voltage quality. There are two common ways to provide the neutral connection: retaining a three-leg inverter structure but splitting the DC-link with a pair of capacitors to provide the fourth wire $[1,2,3]$, and retaining a single DC-link capacitor $[4,5,6]$ by providing a fourth leg (pair of switches). The split-link topology is simpler and uses fewer semiconductors (6 compared to 8 ) but introduces the problem of ensuring close voltage sharing between the split capacitors and the need to attenuate voltage ripple of them. A large neutral current (produced by either unbalanced or nonlinear loads) causes a large perturbation to the split voltages. Such perturbation needs to be compensated for in the phase-voltage control scheme and risks malfunction of the inverter. Voltage balancing controllers, such as dynamic hysteresis current control [3], have been proposed to overcome the problem but the zero-sequence current can still cause large DC voltage imbalance. The voltage deviation can be attenuated by using larger DC-link capacitors but with an obvious penalty in cost and size. The split-link topology requires that the phase-voltage peak is less than or equal to the split DC-link voltage (normally half the total DC-link voltage) whereas the 4leg inverter can allow a line-voltage peak equal to the half the total DC-link voltage. This gives an approximately $15 \%$ advantage in DC voltage utilisation in favour of the 4-leg inverter. Another factor to consider in inverter selection is the high-frequency common-mode voltages with respect to ground produced by the switching. Since there are significant parasitic capacitances between the DC busbars, packages, heat-sinks and ground, there can be significant common-mode current flows through long paths involving ground. These are known to be a source of EMC problems [7]. In this paper, a proposal is made to improve the voltage utilisation of the split-link inverter when fitted with an active balancer. The aim is to retain the EMC advantage of this structure and to extend the use of the active 
balancing circuit beyond just maintaining equal split voltages to modulating these voltages to achieve the same DC voltage utilisation as the 4-leg structure. The resulting inverter has the attractive EMC properties of the split-link 3-leg inverter combined with the better voltage utilisation of the 4-leg inverter. It will use the same number of switches as the 4-leg inverter.

The paper will establish the required form of split voltage modulation to obtain maximum DC voltage utilisation. It will then discusses how the capacitors and balancing circuit inductor are chosen and how the split voltage controller can be designed using a plug-in repetitive control scheme $[8,9]$. The chosen design is verified experimentally. A circuit simulation is used to verify that the commonmode voltage imposed across the parasitic capacitance of the DC-link, and the resulting current, is less onerous than in a 4-leg inverter.

\section{COMPARISON OF 4-WIRE INVERTER TOPOLOGIES}

In simple terms, the role of a 4-wire inverter is to produce a balanced set of phase voltages with respect to neutral.

$$
\begin{aligned}
& V_{a n}(t)=V_{1} \sin \left(2 \pi f_{1} t\right) \\
& V_{b n}(t)=V_{1} \sin \left(2 \pi f_{1} t-\frac{2}{3} \pi\right) \\
& V_{c n}(t)=V_{1} \sin \left(2 \pi f_{1} t+\frac{2}{3} \pi\right)
\end{aligned}
$$

To achieve this with a split-link 3-leg inverter requires the total DC-link voltage to be

$$
V_{D C} \geq 2 V_{1}
$$

This assumes that total DC voltage, $V_{D C}$ is split equally to form the two busbar voltages, $V_{+}$and $V_{-}$, as illustrated in Fig. 1, where $V_{+}=-V_{-}$and $V_{D C}=V_{+}-V_{-}$.

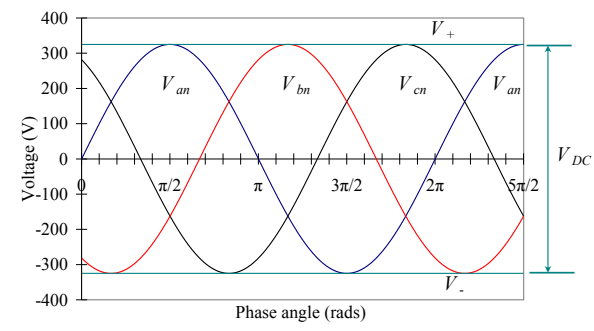


Fig.1 Illustration of the DC-link voltage required for phase voltages with an amplitude of $330 \mathrm{~V}($ peak).

An advantage of the 4-leg inverter is that when space-voltage vector modulation, SVM, is applied, the DC voltage utilisation (defined as the maximum phase voltage magnitude relative to the DC-link voltage) can be increased by approximately $15 \%$ compared to the three-leg, split-link case [4]. SVM applied to 3-wire inverters also has this advantage compared to carrier-based PWM with a sinusoidal reference [10]. However, in 3-wire carrier-based PWM the same 15\% advantage can be achieved by adding a zero-sequence third harmonic term $[11,12]$ to the reference for the PWM. This term will be present in the inverter phase voltages but not present in the line voltages. These two methods are equivalent under certain circumstances and extensive research comparing and contrasting the methods is available $[12,13,14]$. It is not possible to use injection of a third harmonic reference term with a 4wire inverter because the injected signal will also be present in the phase voltage of the loads. Thus, in the 4-wire case, SVM of a 4-leg inverter has a voltage utilisation advantage (of $15 \%$ ) over carrierbased PWM of a split-link 3-leg inverter.

In the split-link 3-leg inverter, the inverter DC busbars are at well defined voltages (the capacitor voltages) with respect to neutral and are not subject to significant common mode voltage with respect to ground if the neutral is well grounded. In contrast, in the 4-leg design the busbars are subject to high frequency voltage transitions with respect to neutral and ground as the fourth leg connects the two busbars to neutral in an alternating pattern at the switching frequency. Proposals have been made to reduce the common mode voltage problem of the 4-leg inverter. For instance, use of the zero vectors can be avoided $[15,16]$ but this also reduces the DC-link utilisation.

On the basis of EMC performance, it would be attractive to choose the split-link 3-leg inverter. To overcome voltage balancing problem, it is possible to fit an active balancing circuit to the split-link using two additional semiconductor switches (the equivalent of a fourth leg) so that a current can be injected into the split capacitors. This approach was discussed in [17] and a control solution provided. 


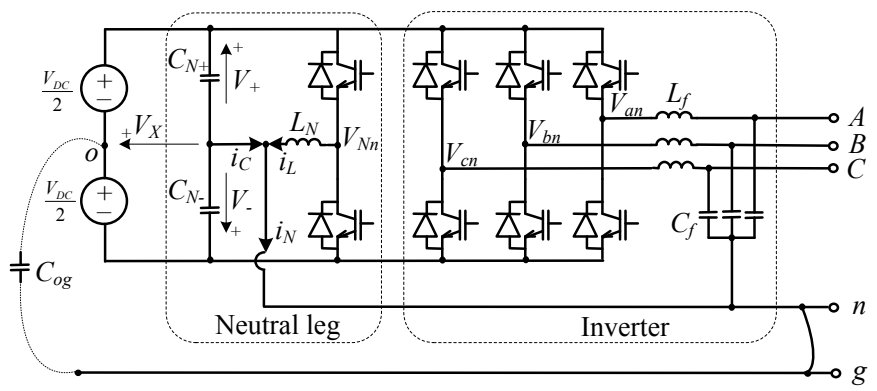

Fig.2: Actively-balanced split-link inverter.

The active control of the split-link can also yield a reduced capacitor size over the passively balanced split-link. The actively-balanced split-link circuit is shown in Fig. 2. The pair of capacitors is the key element, the split voltage sources are for analysis purposes only and in practice a single power source would be present. It has been assumed that the neutral line is solidly connected to ground but this connection could be replaced with a grounding impedance. The parasitic capacitors between each busbar and ground have been reduced to a single capacitance, $C_{o g}$, between the midpoint of the source and ground. It is clear that connecting the split-point to neutral and indirectly to ground prevents the parasitic capacitors being exposed to large voltage transitions.

A shortcoming of the actively-balanced split-link inverter is that the number of semiconductor switches is equal to that of the four-leg inverter but the DC voltage utilisation is only that of the splitlink 3-leg inverter (in other words, the $15 \%$ advantage of the fourth leg is not achieved). However, this is on the assumption that the DC-link voltage is equally split and the offsets of two busbar voltages are fixed. The proposal in this paper is to modulate a busbar offset voltage so as to allow higher maximum phase voltages.

\section{OPTIMAL MODULATION OF THE BUSBAR OFFSET VOLTAGE}

The busbar offset voltage $V_{X}$, shown in Fig. 2, is defined as the displacement of the notional midpoint, $o$, from the split-point of the DC-link ( $V_{X}=V_{o n}$ in this topology). It can be expressed as offset, 


$$
V_{X}=V_{+}-\frac{1}{2} V_{D C}=V_{-}+\frac{1}{2} V_{D C}
$$

or, equivalently,

$$
V_{X}=\frac{V_{+}+V_{-}}{2} .
$$

If the DC-link voltage is equally split, $V_{X}$ is zero. $V_{X}$ will be modulated to ensure that the two busbar voltages are sufficient to establish the required positive and negative peaks of the phase voltages.

$$
\begin{aligned}
& V_{+} \geq V_{\max }(t)=\max \left(V_{a n}(t), V_{b n}(t), V_{c n}(t)\right) \\
& V_{-} \leq V_{\min }(t)=\min \left(V_{a n}(t), V_{b n}(t), V_{c n}(t)\right)
\end{aligned}
$$

The total DC-link voltage required under this condition, $V_{D C}^{\prime}$, is the difference between the busbar voltages:

$$
V_{D C}^{\prime} \geq V_{\max }(t)-V_{\min }(t)
$$

An obvious method to obtain a minimum DC voltage which fulfils (4) is for $V_{X}$ to follow the arithmetic mid-point of $V_{\max }(t)$ and $V_{\min }(t)$ :

$$
V_{X}(t)=\frac{1}{2}\left(V_{\max }(t)+V_{\min }(t)\right)
$$

Fig. 3 illustrates the variation of $V_{X}, V_{+}$and $V_{-}$. It can be seen that the new required DC voltage, $V_{D C}^{\prime}$ is less than that required in Fig. 1 where no modulation of $V_{X}$ occurred. The improvement in DC voltage utilisation can be quantified by considering the segment from $\pi / 6$ to $\pi / 2$ as an example. In this segment $V_{\max }(t)=V_{a n}(t)$ and $V_{\min }(t)=V_{b n}(t)$. Equation (4) becomes:

$$
\begin{aligned}
V_{D C}^{\prime} & \geq V_{a n}(t)-V_{b n}(t) \\
& =V_{1} \sin \left(2 \pi f_{1} t\right)-V_{1} \sin \left(2 \pi f_{1} t-\frac{2}{3} \pi\right)
\end{aligned}
$$




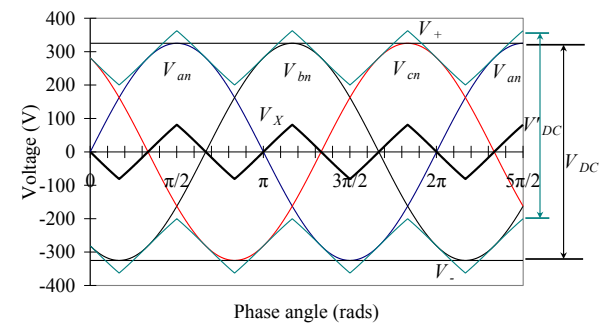

Fig.3 Illustration of reduced $V_{D C}$ when $V_{X}$ tracks the mid-point of the phase voltage extremes.

In other words, $V_{D C}^{\prime}$ must exceed the line voltage peak and this occurs at $\pi / 3$ and has a value of $\sqrt{3} V_{1}$.

The required DC voltage is:

$$
V_{D C}^{\prime} \geq \sqrt{3} V_{1}=\frac{\sqrt{3}}{2} V_{D C} \approx \frac{1}{1.15} V_{D C}
$$

Thus the $15 \%$ advantage in DC voltage utilisation of the 4-leg inverter has been achieved here also. It can be verified that equations (5) and (7) fulfil the conditions in (3).

The waveform of $V_{X}$ produced by (5) and illustrated in Fig. 3 consists of segments of sine-waves with a period of one third of the fundamental but also containing higher triplen harmonics. It would be challenging to reproduce this as a voltage on the DC-link capacitors. An alternative would be to use a sinewave of the same period, i.e., a third harmonic, as illustrated in Fig. 4 and (8).

$$
V_{X}(t)=V_{3} \sin \left(-3 \cdot 2 \pi f_{1} t\right)
$$

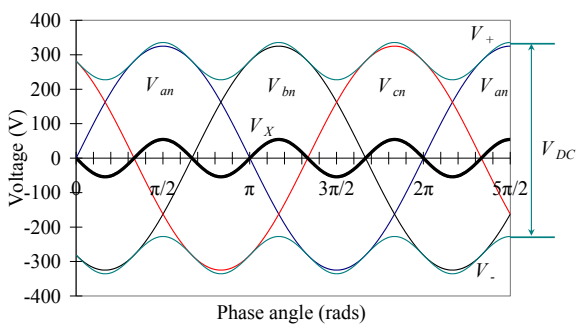

Fig.4 Illustration of reduced $V_{D C}$ when $V_{X}$ is third harmonic. 
As shown in appendix A, the amplitude of third harmonic that yields the best DC voltage utilisation is one sixth of the amplitude of the fundamental, and it yields an advantage of $15 \%$ over the standard split-link arrangement. The principle is the same as injecting a third harmonic term in 3-wire 3-leg inverters [8] but here the third harmonic is applied to the busbar potentials.

The modulating signal used for each phase voltage must now be modified to account for the variation of the busbar offset. The phase- $a$ voltage as function of switch duty-cycle, $d_{a}$, or depth of modulation, $m_{a}$, is defined in (9). (Note: $0 \leq d_{a} \leq 1 ; d_{a}=1 / 2\left(1+m_{a}\right)$ and $-1 \leq m_{a} \leq 1$ )

$$
\begin{aligned}
V_{a n} & =d_{a} \cdot V_{+}+\left(1-d_{a}\right) \cdot V_{-} \\
& =\frac{1}{2}\left(1+m_{a}\right) \cdot V_{+}+\frac{1}{2}\left(1-m_{a}\right) \cdot V_{-}=\frac{1}{2} m_{a} V_{D C}+V_{X}
\end{aligned}
$$

To achieve a desired phase voltage requires:

$$
m_{a}=\frac{2}{V_{D C}}\left(V_{a n}^{r e f}-V_{X}\right)
$$

\section{NEUTRAL LEG MODELLING AND CONTROL}

\section{A. Modelling of the neutral leg}

The busbar offset voltage can be controlled by injecting a current through the inductor $L_{N}$ under the influence of the $4^{\text {th }}$ leg voltage $V_{N n}$, as shown in Fig. 2. The capacitor current is composed of the inductor current used for control and the neutral current required by the load, which here is considered as a disturbance. The following equations apply.

$$
\begin{gathered}
i_{C}=C_{N+} \frac{d V_{+}}{d t}+C_{N-} \frac{d V_{-}}{d t} \\
=2 C_{N} \frac{d V_{X}}{d t} \text { if } C_{N+}=C_{N-}=C_{N} \\
L_{N} \frac{d i_{L}}{d t}=V_{N n}=d_{N} V_{+}+\left(1-d_{N}\right) V_{-} \\
=m_{N} \frac{V_{D C}}{2}+V_{X}
\end{gathered}
$$

where $d_{N}$ is the duty-cycle of the neutral leg transistors and $m_{N}=2 d_{N}-1$ is the depth of modulation.

The state equations of the system are: 


$$
\left\{\begin{array}{l}
2 C_{N} \dot{V}_{X}=i_{N}-i_{L} \\
L_{N} \dot{i}_{L}=V_{X}+\frac{V_{D C}}{2} m_{N}
\end{array}\right.
$$

\section{B. Selection of split-link components}

It is now necessary to choose suitable component values. Clearly it is advantageous to choose small valued components for reasons of cost and volume but the following additional factors need to be considered.

(a) The cut-off frequency of the neutral leg circuit must be above $3 f_{l}$ so as to be able to control $V_{X}$ to follow the $3^{\text {rd }}$ harmonic reference. Ignoring the external disturbance $i_{N}$, the transfer function from the depth of modulation $m_{N}$ to busbar offset voltage $V_{X}$ can be obtained from (12),

$$
\frac{V_{X}}{m_{N}}(s)=\frac{V_{D C}}{2} \cdot \frac{1}{1+2 C_{N} L_{N} s^{2}}
$$

This cut-off frequency condition therefore determines the product of the inductor and capacitor values and shows that small values are required.

(b) It is desirable that the magnitude of the $3^{\text {rd }}$ harmonic current required to create $V_{X}$ should not be large. This condition indicates that within the confines of condition (a) the capacitor size should be reduced. The amplitude of the $3^{\text {rd }}$ harmonic current required for a voltage of $\left|V_{X}\right|=\frac{1}{6} V_{1}$ is:

$$
\left|I_{f_{3}}\right|=\frac{1}{6} V_{1} \cdot 2 \pi \cdot 3 f_{1} \cdot C_{N}=\pi f_{1} C_{N} V_{1}
$$

A disadvantage of choosing $C_{N}$ small for this reason is that $i_{N}$ will have a large effect on the busbar voltages and so good disturbance rejection from the controller is needed.

(c) There will also be switching frequency ripple present in the capacitor voltages and it is desirable to keep this small. Contrary to conditions (a) and (b), condition (c) indicates that a large capacitor value is desirable. An estimate of the amplitude of the ripple can be gained by considering the fundamental term of a square-wave voltage of amplitude $V_{D C}$ and frequency of $f_{s}$ and the effect an $L C$ circuit has in attenuating this. Clearly, both $L_{N}$ and $C_{N}$ should be large to keep the ripple small. 


$$
\left|V_{\text {Ripple }}\right| \approx \frac{V_{D C}}{4 \pi^{3} C_{N} L_{N} f_{s}^{2}}
$$

\section{Controller design}

Equation (12) forms the basis of a state-space model of the neutral leg system. We choose the state vector to be $\mathbf{x}=\left[\begin{array}{ll}V_{X} & \dot{V}_{X}\end{array}\right]$ and treat $i_{N}$ as a disturbance term in vector $\delta$. This choice of state vector will remove the need to measure $i_{L}$ for state-feedback and leave only $V_{X}$ to be measured.

$$
\dot{\mathbf{x}}=\mathbf{A x}+\mathbf{B} u+\boldsymbol{\delta}
$$

where $\quad \mathbf{A}=\left[\begin{array}{cc}0 & 1 \\ 1 /-2 C_{N} L_{N} & 0\end{array}\right], \quad \mathbf{B}=\left[V_{D C} /-4 C_{N} L_{N}\right], u=m_{N}$, and $\quad \boldsymbol{\delta}=\left[\begin{array}{l}\dot{i}_{N} / 2 C_{N} \\ 0\end{array}\right]$.

A controller was designed to force the busbar offset voltage to track the $3^{\text {rd }}$ harmonic reference voltage. A deadbeat controller supplemented by a repetitive controller was chosen to give good tracking and the ability to reject periodic neutral current disturbance [8]. The general arrangement is shown in Fig.

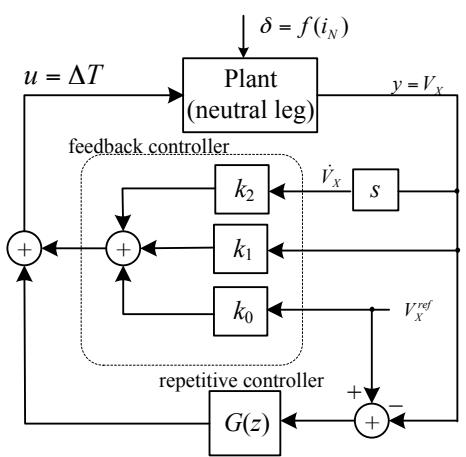

Fig.5. The control system. A deadbeat feedback controller and a repetitive controller are connected in parallel.

5 . 
A discrete-time controller was designed using the procedure outlined here. In discrete-time from the state-space representation (ignoring the disturbance) is:

$$
\left[\begin{array}{c}
V_{X}(k+1) \\
\dot{V}_{X}(k+1)
\end{array}\right]=\left[\begin{array}{ll}
\phi_{11} & \phi_{12} \\
\phi_{21} & \phi_{22}
\end{array}\right]\left[\begin{array}{l}
V_{X}(k) \\
\dot{V}_{X}(k)
\end{array}\right]+\left[\begin{array}{l}
g_{1} \\
g_{2}
\end{array}\right] \Delta T(k)
$$

where

$$
\begin{array}{ll}
\phi_{11}=1-\frac{T^{2}}{4 C_{N} L_{N}}, & \phi_{12}=T, \\
\phi_{21}=-\frac{T}{2 C_{N} L_{N}}, & \phi_{22}=1-\frac{T^{2}}{4 C_{N} L_{N}}, \\
g_{1}=-\frac{V_{d c}}{4 C_{N} L_{N}} T, & g_{2}=-\frac{V_{d c}}{4 C_{N} L_{N}},
\end{array}
$$

$T$ is the sampling interval which is chosen to be the switching period $1 / f_{s}$, and $\Delta T=m_{N} T$ is the width of the switching voltage pulse applied.

The output equation is $y(k)=V_{X}(k)$. A suitable control law is:

$$
\Delta T(k)=k_{0} V_{X}^{r e f}(k)+k_{1} V_{X}(k)+k_{2} \dot{V}_{X}(k)
$$

where $\left\{\begin{array}{l}k_{0}=1 / g_{1} \\ k_{1}=-\phi_{11} / g_{1} \\ k_{2}=-\phi_{12} / g_{1}\end{array}\right.$ and $V_{X}^{r e f}(k)$ is the reference value.

Under ideal conditions this deadbeat control will yield an output at the end of the sampling period equal to the reference value:

$$
Y(k+1)=V_{X}(k+1)=V_{X}^{r e f}(k)
$$

In practice, there are disturbances and uncertainties in the circuit parameters and perfect deadbeat control can not be achieved. A plug-in repetitive controller can be connected in parallel with an existing controller without affecting its stability [8]. The repetitive controller will attenuate (ideally to zero) disturbances of the chosen period including the harmonic terms. The transfer function of the controller in the discrete-time form is:

$$
G(z)=k_{g} \frac{Q(z) \cdot z^{-\left(N-N_{2}\right)}}{1-Q(z) \cdot z^{-N}}
$$


where $k_{g}$ is the gain; $N=f_{\mathrm{s}} / f_{1} ; N_{2}$ is the delay number; $Q(z)=0.25 \cdot\left(z+2+z^{-1}\right)$ is a first order filter.

\section{EVALUATION AND ANALYSIS}

The proposed variable busbar offset strategy was tested experimentally using an inverter with the circuit arrangement of Fig. 2 and with parameters as set out in Table I. The control was implemented on a DSP. To illustrate some features, the same system was simulated in PSCAD/EMTDC.

The DC-link voltage was chosen on the basis of producing a peak phase voltage of $330 \mathrm{~V}$. With the busbar offset voltage modulated with a peak of $55 \mathrm{~V}$, this gives a required DC link voltage of $572 \mathrm{~V}$. To accommodate semiconductor and filter voltage drops, a link voltage of $V_{D C}=585 \mathrm{~V}$ was chosen.

For a $50 \mathrm{~Hz}$ system, the split-point is modulated at $3 f_{1}=150 \mathrm{~Hz}$ and the filter cut-off is constrained according to (13),

$$
C_{N} L_{N}<\frac{1}{2 \cdot\left(2 \pi \cdot 3 f_{1}\right)^{2}}=5.623 \times 10^{-7} \mathrm{~s}^{2}
$$

The maximum ripple at switching frequency $(10 \mathrm{kHz})$ of the busbar offset voltage was chosen to be 1 $\mathrm{V}$ and (15) further constrains the filter design,

$$
C_{N} L_{N}>\frac{V_{D C}}{4 \pi^{3} V_{\text {Ripple }} f_{s}^{2}}=4.717 \times 10^{-8} \mathrm{~s}^{2}
$$

Choosing a value of $1.5 \mathrm{~A}$ for the third harmonic current amplitude in the link capacitors gives, via (14), a limit for the capacitance,

$$
C_{N}<\frac{I_{f_{3}}}{\pi f_{1} V_{1}}=28.94 \mu \mathrm{F}
$$

A value of $C_{N}=25 \mu \mathrm{F}$ was chosen. The compromise chosen for the filter cut-off was $f_{c}=450 \mathrm{~Hz}$ which led to a choice of $L_{N}=2.5 \mathrm{mH}$. The resultant voltage ripple is $V_{\text {Ripple }}=0.704 \mathrm{~V}$ and capacitor current of $I_{f_{3}}=1.296$ A. Deadbeat control design according to (17) gave controller parameters of: $k_{0}=-4.2735 \times 10^{-6}, k_{1}=4.1026 \times 10^{-6}$, and $k_{2}=4.2735 \times 10^{-10}$. 
Table I Inverter parameters.

\begin{tabular}{|c|c|c|c|}
\hline Output power & $30 \mathrm{~kW}$ & Neutral capacitor $C_{N^{+}}, C_{N^{-}}$ & $25 \mu \mathrm{F}$ \\
\hline Phase voltage & $330 \mathrm{~V}$ (peak) & Neutral inductor $L_{N}$ & $2.5 \mathrm{mH}$ \\
\hline AC frequency & $50 \mathrm{~Hz}$ & Filter capacitor $C_{f}$ & $50 \mu \mathrm{F}$ \\
\hline Switching frequency & $10 \mathrm{kHz}$ & Filter inductor $L_{f}$ & $1.35 \mathrm{mH}$ \\
\hline
\end{tabular}
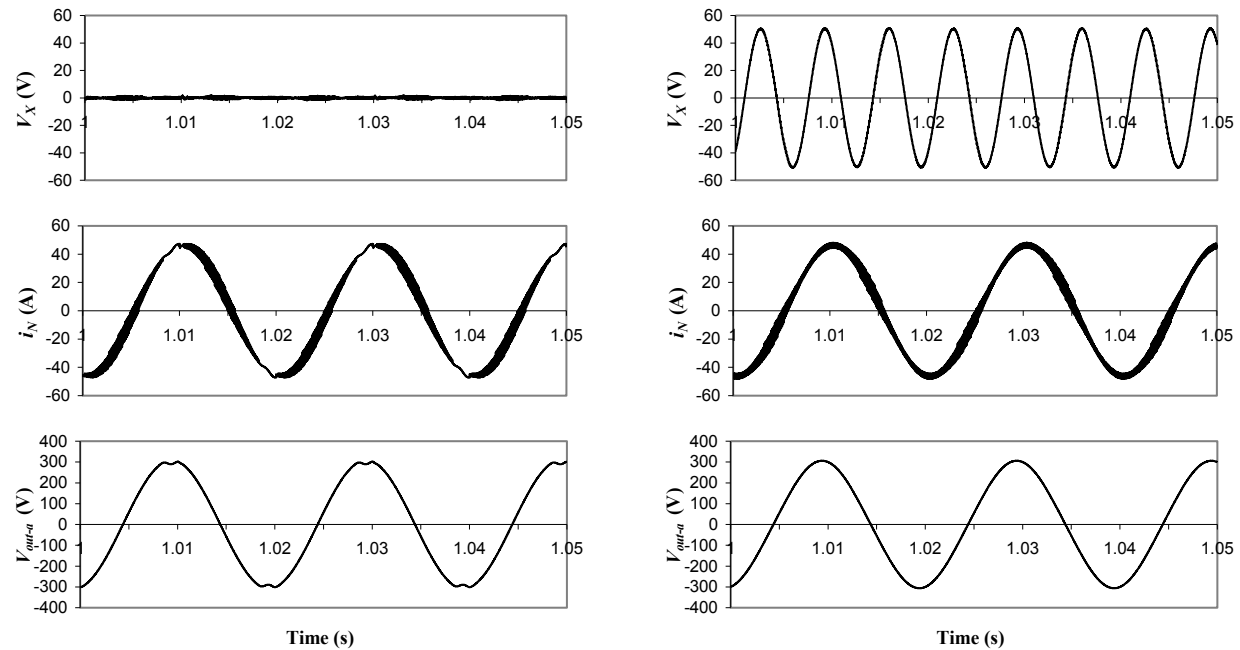

(a) with un-modulated busbar offset.

(b) with third harmonic busbar offset .

Fig.6: Simulation results. From top to bottom: busbar offset voltage, $V_{X}$; neutral current, $i_{N}$; and phase- $a$ output voltage after the LC filter, $V_{A n}$.

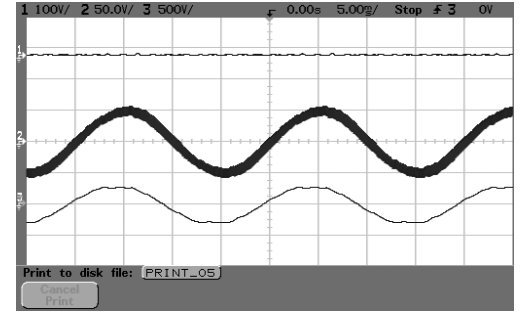

(a) with un-modulated busbar offset.

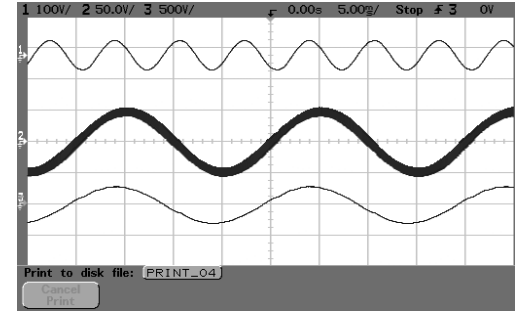

(b) with third harmonic busbar offset.

Fig.7: Experimental results. From top to bottom: busbar offset voltage, $V_{X}, 100 \mathrm{~V} / \mathrm{div}$ (measured with potential divider of two $47 \mathrm{k} \Omega$ resistors between $V_{+}$and $V$. busbars); neutral current, $i_{N}, 50 \mathrm{~A} /$ div and phase- $a$ output voltage after the LC filter, $V_{A a}, 500 \mathrm{~V} / \mathrm{div}$. Time axis is $5 \mathrm{~ms} / \mathrm{div}$ 
A severe test of the ability of the controller to maintain the correct busbar offset voltage is to test the 4-wire system with a single-phase load (which is an extremely unbalanced three-phase load) with return of current via the neutral. A resistive-inductive load of $5.76 \Omega$ in series with $8 \mathrm{mH}$ was chosen for the test giving a neutral current of approximately $50 \mathrm{~A}$. With $V_{D C}$ set at $585 \mathrm{~V}$ and $V_{1}$ at $330 \mathrm{~V}$, the modulation of the phase legs will saturate if the busbar offset voltage is not varied $\left(V_{X}=0\right)$ and in turn the output voltage of the filter, $V_{A n}$ will be distorted. It's total harmonics distortion (THD) is $2.83 \%$. This is illustrated in simulation in Fig 6(a) and experimentally verified in Fig. 7(a). It is worth noting in passing that the active-balancer has successfully held the busbar offset voltage at zero despite the large amplitude neutral current. Fig. 6(b) and 7(b) show that with the busbar offset voltage modulated with a $55 \mathrm{~V}$ at $150 \mathrm{~Hz}$, the output voltage is not distorted because the link voltage is better utilized. The THD of the output voltage is $1.35 \%$. 

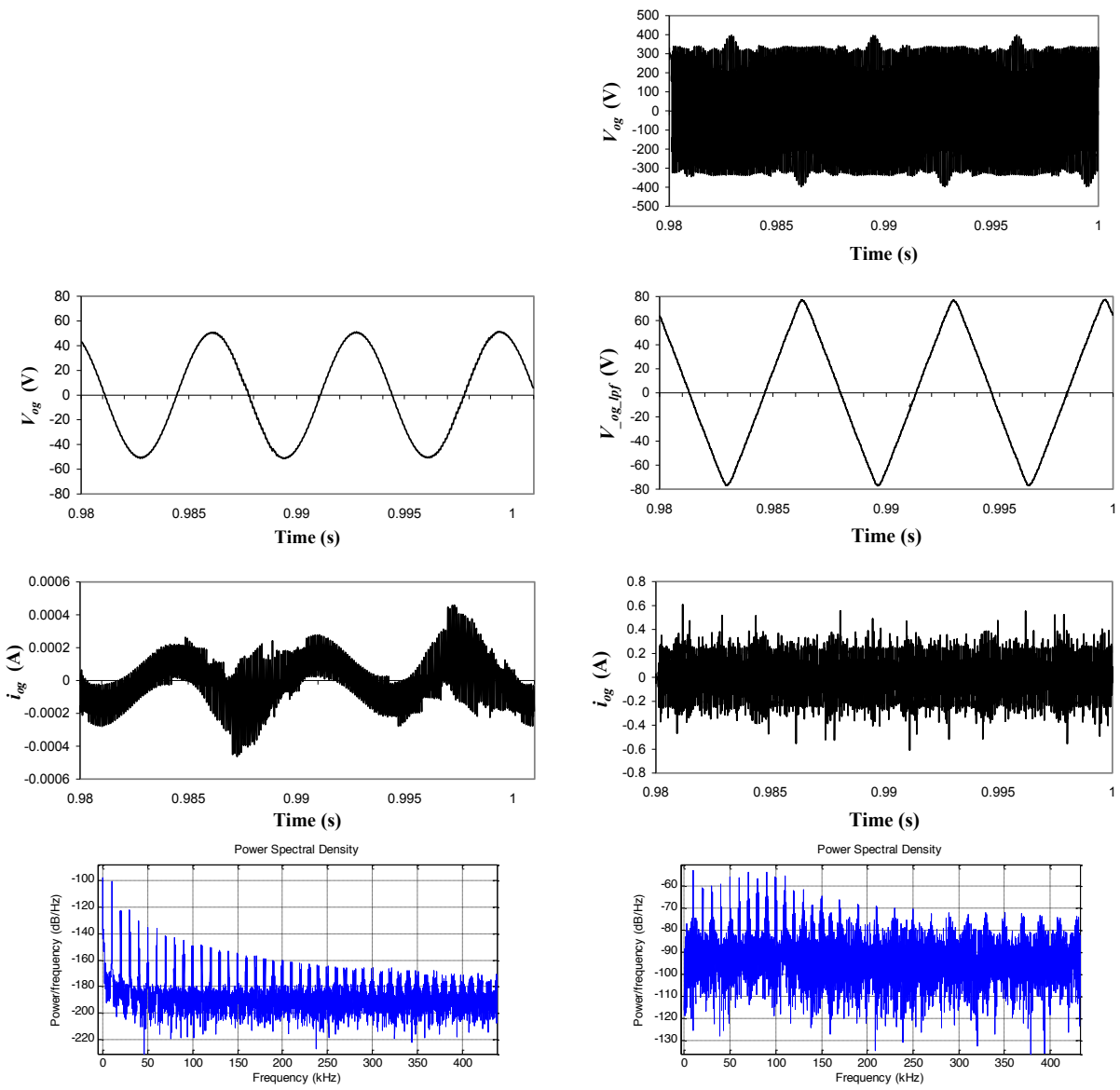

(a) Split-link inverter with modulated busbar offset.

(b) 4-leg inverter with SVM

Fig.8: Simulation of common-mode voltage $V_{\text {og }}$ (including a filtered version in (b)) and common-mode currents, $i_{o g}$ in time and frequency domains.

An important reason to adopt the split-link 4-wire topology is to improve EMC through reduction of high frequency voltage variation of the inverter busbars with respect to ground. This was tested in simulation and is shown in Fig. 8. The common-mode voltage, $V_{\text {og }}$, applied across the link-to-ground parasitic capacitance, $C_{o g}$, of the inverter was studied for both the split-link inverter and a 4-leg inverter using a standard symmetrical SVM switching technique [4]. The capacitance was set to $2.7 \mathrm{nF}$. Because the current through this capacitor flows in large area common-mode paths, it can be a serious source of EMC problems. Its spectrum is therefore a relative measure of EMC performance. 
The common-mode voltage, $V_{\text {og }}$, in the split-link inverter is the third-harmonic term $(55 \mathrm{~V}$ at 150 $\mathrm{Hz}$ ) plus the ripple voltage remaining after filtering by $C_{N}$ and $L_{N}$ as described by equation (15). This is shown in Fig. 8(a) which reveals that the common mode current is approximately $0.5 \mathrm{~mA}$. For the 4leg inverter with SVM, $V_{\text {og }}$ is rectangular wave of $330 \mathrm{~V}$ at $10 \mathrm{kHz}$, as seen in the top plot of Fig. 8(b), which is rich in switching frequency terms but also has an underlying low frequency component. A notch filter of $\frac{1}{s} \cdot\left(1-e^{-\frac{s}{10000}}\right) \cdot \frac{10000}{s+10000}$ was used to remove the $10 \mathrm{kHz}$ switching frequency to reveal the low frequency component, $V_{\text {og_lpf }}$ as also shown in Fig.8 (b). The total common-mode current is much higher at $0.4 \mathrm{~A}$. The frequency spectra of $i_{\text {og }}$ show that the split-link inverter has a switching frequency component more than $40 \mathrm{~dB}$ below that of the 4-leg inverter and that the switching frequency harmonics are some $80-90 \mathrm{~dB}$ lower to beyond $50 \mathrm{kHz}$. The waveforms of output voltages for these two cases were also compared. The THDs figures are similar and both are, small at $1.35 \%$ for the split-link inverter and $1.2 \%$ for the $4-\operatorname{leg}$ inverter, There is not much difference in spectra of the output voltages especially in the high frequency ranges but a relatively high $3^{\text {rd }}$ harmonic term $(150 \mathrm{~Hz})$ was found for the split-link inverter and resulted in a slightly higher THD, as shown in Fig.9. This can be explained using equation (9) in that the $3^{\text {rd }}$ harmonic busbar offset voltage would be present in the output voltage, although most of this componentwill have been removed by modifying the depth of modulation, $m_{\underline{a}}$. It should be noted that only open loop control was used for producing the output voltages for the two inverter topologies in this paper. If closed loop control is used, THDs can be reduced further for both the split-link inverter with the modulated busbar offset and the 4-leg inverter with SVM.
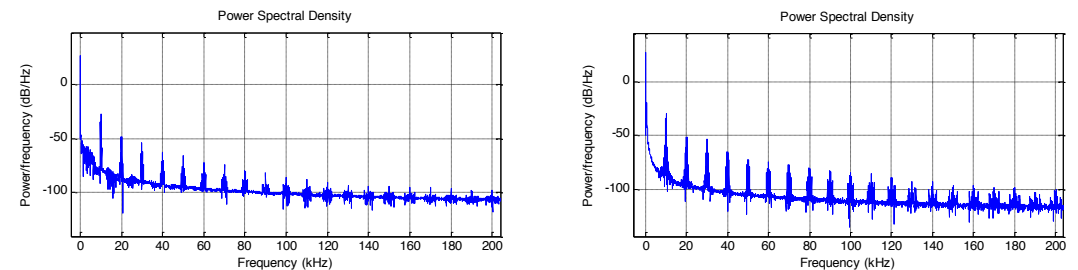

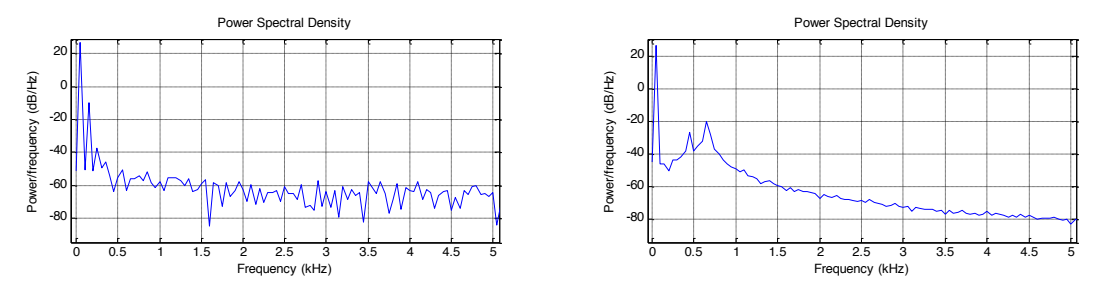

(a) Split-link inverter with modulated busbar offset.

(b) 4-leg inverter with SVM.

Fig.9: Power spectrum density analysis for phase output voltage $V_{A n}$ :

\section{CONCLUSIONS}

It has been shown that it is feasible to modulate the busbar offset voltage of a split-link, 3-leg, 4-wire inverter using an active balancing circuit and by doing so the DC voltage utilisation can be improved to match that of a SVM 4-leg inverter. No advantage in number of switches is achieved because the active-balancer is the equivalent of a fourth leg but a significant advantage is found in the spectrum of the voltage across any parasitic capacitance between the DC-link and ground. The split-link inverter has much lower amplitude common-mode voltages at switching frequency since comprising only the ripple across the split-link capacitors appears rather than the full square-wave voltage of the fourth leg. It has been shown in simulation and experiment that a deadbeat controller with an additional repetitive controller (for disturbance rejection) can successfully create the correct reference voltage for the busbar offset. That reference voltage has been established as a third harmonic voltage of one sixth the amplitude of the phase voltage fundamental.

\section{REFERENCES}

[1] M. Aredes, J. Hafner and K. Heumann, "Three-phase four-wire shunt active filter control strategies," IEEE Trans. Power Electronics, Vol. 12, No. 2, pp. 311-318, 1997

[2] P. Salmeron, J.C. Montano, J.R. Vazquiez, and A. Perez, "Compensation in nonsinusoidal, unbalanced three-phase four-wire systems with active power-line conditioner," IEEE Trans. Power Electronics, Vol. 19, No. 4, pp. 1968-1974, 2004 
[3] P. Verdelho, and G.D. Marques, "Four-wire current-regulated PWM voltage converter," IEEE Trans. Industrial Electronics, Vol. 45, No. 5, pp. 761-770, 1998.

[4] R. Zhang, V. H. Prasad, D. Boroyevich, and F.C. Lee, "Three-dimensional space vector modulation for four-leg voltage-source converters," IEEE Trans. Power Electronics, Vol. 17, No. 3, pp. 314-326, 2002.

[5] C.A. Quinn, N. Mohan, and H. Mehta, "A four-wire, current-controlled converter provides harmonic neutralization in three-phase, four-wire systems," IEEE Applied Power Electronics Conference and Exposition, pp.841 - 846, 7-11 March 1993.

[6] S.M. Ali, and M.P. Kazmierkowski, "Current regulation of four-leg PWM-VSI," IEEE 24th Annual Industrial Electronics Conference (IECON '98), Vol. 3, pp. 1853 - 1858, 31 Aug.-4 Sept. 1998.

[7] K. Mainali, R. Oruganti, K. Viswanathan, and S. P. Ng, "A Metric for Evaluating the EMI Spectra of Power Converters," IEEE Trans. Power Electronics, Vol. 23, No. 4, pp. 2075-2081, July 2008 .

[8] K.L. Zhou, D.W. Wang, and K.S. Low, "Periodic errors elimination in CVCF PWM DC/AC converter systems: repetitive control approach," IEE Proc. Control Theory Appl., Vol. 147, No. 6, pp.694-700, 2000

[9] X. H. Wu, S. K. Panda, and J. X. Xu, "DC Link Voltage and Supply-Side Current Harmonics Minimization of Three Phase PWM Boost Rectifiers Using Frequency Domain Based Repetitive Current Controllers," IEEE Trans. Power Electronics, Vol. 23, No. 4, pp. 1987-1997, 2008

[10] H.W. van der Broeck, H.C. Skudelny, and G.V. Stanke, "Analysis and realization of a pulse modulator based on voltage space vectors," IEEE Trans. Industrial Applications, Vol. 24, Jan./Feb. 1988, pp. $142-150$ 
[11] J.A. Houldsworth, and D.A. Grant, "The use of harmonic distortion to increase the output voltage of a three-phase PWM inverter," IEEE Trans. Industry Application, Vol. IA-20, No.5, pp.12241228,1984

[12] V. Blasko, "Analysis of a hybrid PWM based on modified space-vector and triangle-comparison methods," IEEE Trans. Industry Application, Vol. 33, No.3, pp.756-764, 1997

[13] S.R. Bowes, and Y.S. Lai, "The relationship between space-vector modulation and regularsampled PWM," IEEE Trans. Power Electronics. Vol. 44, No. 5, pp.670-679, October 1997

[14] K.L. Zhou, and D.W. Wang, "Relationship between space-vector modulation and three-phase carrier-based PWM: a comprehensive analysis," IEEE Trans. Power Electronics. Vol. 49, No. 1, pp.186-196, February 2002

[15] C. Liu, J. Lai, F.C. Lee, D. Chen, and R. Zhang, "Common-mode components comparison for different SVM schemes in three-phase four-legged converter," The Third International Conference on Power Electronics and Motion Control, 2000. Vol. 2, pp.633 - 638, 15-18 Aug. 2000

[16] A.L. Julian, G. Oriti, and T.A. Lipo, "Elimination of common-mode voltage in three-phase sinusoidal power converters," IEEE Trans. Power Electronics, Vol.14, No. 5, pp.982-989, Sept. 1999

[17] Q.C. Zhong, J. Liang, C. Feng, G. Weiss, and T.C. Green, " $\mathrm{H}^{*}$ control of the neutral point in four-wire three-phase DC-AC converters," IEEE Trans. Industrial Electronics, Vol. 53, No. 5, pp. 1594-1602, October 2006

\section{APPENDIX A}

To find the optimal magnitude of third harmonic voltage for the busbar offset modulation it is sufficient to examine the interval from $\pi / 6$ to $\pi / 2$. We seek the magnitude that allows the smallest DC voltage to be used for a given phase voltage. 


$$
\begin{gathered}
V_{+}=\frac{1}{2} V_{D C}+V_{X}(t) \\
\geq V_{a n}(t) \\
V_{D C} \geq 2 V_{a n}(t)-2 V_{X}(t) \\
=2 V_{1} \sin \left(2 \pi f_{1} t\right)+2 V_{3} \sin \left(3 \cdot 2 \pi f_{1} t\right) \\
=2 V_{1}\left(\sin (\theta)+A_{3} \sin (3 \theta)\right)
\end{gathered}
$$

It is convenient to define the third harmonic magnitude relative to the fundamental of the phase voltage, $A_{3}=V_{3} / V_{1}$ and to use the angle $\theta=2 \pi f_{1} t$. The maximum voltage required occurs at the angle where $\frac{d V_{D C}}{d \theta}$ is zero.

$$
\frac{d V_{D C}}{d \theta}=2 V_{1}\left(\cos \theta+3 A_{3} \cos 3 \theta\right)=0
$$

The solutions to (A3) within $\frac{1}{6} \pi$ to $\frac{1}{2} \pi$ are $\theta=\cos ^{-1} 0=\frac{1}{2} \pi$ and $\theta=\cos ^{-1} \sqrt{\frac{9 A_{3}-1}{12 A_{3}}}$. The sign of the second differential will indicate whether a maxima or minima exists.

$$
\frac{d^{2} V_{D C}}{d \theta^{2}}=-2 V_{1}\left(\sin \theta-9 A_{3} \sin 3 \theta\right)
$$

Considering first the case of $\theta=\frac{1}{2} \pi$, the second differential is:

$$
\frac{d^{2} V_{D C}}{d \theta^{2}}=2 V_{1}\left(9 A_{3}-1\right)
$$

Equation (A6) indicates that if $A_{3}>\frac{1}{9}$ then $\theta=\frac{1}{2} \pi$ is a minimum point whereas if $A_{3}<\frac{1}{9}$ then $\theta=\frac{1}{2} \pi$ is a maximum point. When $A_{3}=\frac{1}{9}$ the maximum voltage required is

$$
V_{D C} \geq 1.778 V_{1}
$$

For the second case of $\theta=\cos ^{-1} \sqrt{\frac{9 A_{3}-1}{12 A_{3}}}$, the amplitude must be $A_{3}>\frac{1}{9}$. The second differential and DC voltage required are:

$$
\frac{d^{2} V_{D C}}{d \theta^{2}}=\sqrt{\frac{3 A_{3}+1}{12 A_{3}}} \cdot\left(1-9 A_{3}\right)
$$




$$
V_{D C} \geq 2 V_{1} A_{3}\left(\frac{3 A_{3}+1}{3 A_{3}}\right)^{\frac{3}{2}}
$$

For $A_{3}>\frac{1}{9}, \frac{d^{2} V_{D C}}{d \theta^{2}}<0$ and (A8) will yield the maximum voltage required. Differentiating (A8) with respect to $A_{3}$ and setting the result to be zero will give the values of $A_{3}$ that cause lowest or highest required voltage.

$$
\frac{d V_{D C}}{d A_{3}}=2 V_{1} \cdot\left(\frac{3 A_{3}+1}{3 A_{3}}\right)^{\frac{1}{2}} \cdot\left(\frac{6 A_{3}-1}{6 A_{3}}\right)=0
$$

The solutions to (A9) are $A_{3}=-\frac{1}{3}$ (which can be discarded) and $A_{3}=\frac{1}{6}$, which when substituted into (A8) gives

$$
V_{D C} \geq \sqrt{3} \cdot V_{1} \quad(\mathrm{~A} 10) .
$$

In summary, the first case of a maximum at $\theta=\frac{1}{2} \pi$ using $A_{3}<\frac{1}{9}$ requires $V_{D C} \geq 1.778 V_{1}$ whereas the second case with a maximum at $\theta=\cos ^{-1} \sqrt{\frac{9 A_{3}-1}{12 A_{3}}}$ using $A_{3}=\frac{1}{6}$ requires $V_{D C} \geq 1.731 V_{1}$ and so the second case is preferred. This result is the same as that obtained for the 3-leg, 3-phase inverter. 